\title{
DIAGNOSA PENYAKIT JANTUNG PADA PONSEL MENGGUNAKAN POHON KEPUTUSAN
}

\author{
Febri Maspiyanti \\ Teknik Informatika Universitas Pancasila \\ febri.maspiyanti@univpancasila.ac.id
}

\author{
Jullend Gatc \\ Sistem Informasi Kalbis Institute \\ jullend.gatc@kalbis.ac.id
}

\begin{abstract}
ABSTRAK
Berkembangnya teknologi kini dapat mempermudah seorang praktisi medis untuk mendiagnosa dengan cepat dan tepat apakah seorang pasien menderita penyakit jantung atau tidak layaknya seorang dokter spesialis jantung yang sudah berpengalaman. Hal tersebut dibutuhkan sebagai usaha dalam deteksi dini penyakit jantung. Penelitian ini bertujuan untuk mencari pola dari penyakit jantung dan membangun sebuah aplikasi mobile untuk mendeteksi penyakit jantung berdasarkan Pohon Keputusan (Pohon Keputusan). Dalam penelitian ini digunakan dataset sejumlah 294 data pasien yang terdiri dari 13 atribut dan 1 atribut sebagai kelas. Kami menggunakan age, sex, chest pain type, resting blood pressure, cholesterol, fasting blood sugar, resting ECG, average heart rate, examine induced angina, $T$ or ST oldpeak, ST slope, number of major vessels, general heart rate sebagai input, dan sehat atau sakit sebagai output. Penelitian ini berhasil menghasilkan akurasi sebesar 81,29\% dan mengimplementasikan aturan-aturan yang dihasilkan oleh Pohon Keputusan kedalam aplikasi ponsel.
\end{abstract}

Kata kunci : Penyakit Jantung, Pohon Keputusan, Ponsel.

\section{PENDAHULUAN}

\section{A. Latar Belakang}

Penyakit jantung koroner merupakan salah satu penyakit yang paling berbahaya karena serangannya yang begitu mendadak dengan singkat dapat merenggut nyawa penderitanya. Penyakit jantung merupakan penyebab kematian tertinggi di Indonesia [1]. Angka kematian yang disebabkan oleh penyakit ini semakin meningkat seiring berkembangnya gaya hidup yang tidak sehat di kalangan masyarakat. Banyak hal yang menjadi faktor utama penyebab penyakit jantung, antara lain faktor umur, jenis kelamin, tekanan darah, gula darah, dan kolesterol. Faktor lain seperti jenis kelamin, nyeri dada, EKG dalam keadaan istirahat, dan thallium juga digunakan sebagai tolak ukur untuk mengidentifikasi penyakit jantung.

Proses untuk mendeteksi penyakit jantung koroner umumnya masih menggunakan cara manual yaitu dengan melakukan konsultasi secara langsung ke dokter spesialis penyakit jantung dan melakukan beberapa pemeriksaan laboratorium yang kemudian harus dikonsultasikan lagi dengan dokter spesialis jantung. Untuk melakukan serangkaian pemeriksaan mulai dari konsultasi ke dokter spesialis saja sudah menghabiskan banyak biaya, apalagi ditambah pemeriksaan laboratorium. Bukan hanya itu, dengan jadwal praktik dokter spesialis jantung yang umumnya hanya beberapa jam saja, belum lagi jika kita harus antri, yang artinya kita harus menyesuaikan jadwal kita dengan dokter setiap kali akan melakukan konsultasi ke dokter spesialis jantung.

Penelitian dalam mendiagnosa penyakit dengan menggunakan teknologi komputer semakin meningkat [2]. Pohon Keputusan, Fuzzy Logic, Artificial Neural Network, algoritma Genetic merupakan beberapa teknik yang dapat digunakan untuk mendapatkan suatu sistem yang mampu memberikan pola suatu penyakit berdasarkan data training yang diberikan. 
Selain algoritma-algoritma yang telah disebutkan sebelumnya, teknik lain yang dapat digunakan adalah Algoritma C 4.5. Algoritma C 4.5 merupakan algoritma yang mampu mengolah continuous data [14] yang memiliki banyak kelebihan diantaranya yaitu proses lebih cepat, akurasi tinggi, dan hasil lebih mudah untuk dimengerti dan diimplementasi [3] [4].

Dengan makin maraknya penelitian dalam deteksi penyakit jantung diharapkan dapat menekan angka kematian akibat kurangnya tenaga medis yang mampu mendiagnosa seorang pasien menderita penyakit jantung atau tidak.Apalagi dalam perkembangan teknologi mobile yang semakin pesat, diharapkan keberadaan dokter spesialis yang sangat terbatas dapat digantikan dengan suatu sistem otomatis yang memiliki kemampuan layaknya seorang dokter spesialis.Sistem otomatis tersebut diharapkan mampu menggantikan keberadaan dokter spesialis ketika dalam kondisi tertentu sebagai upaya untuk diagnosa dini penyakit jantung.

\section{LANDASAN TEORI}

\section{A. Jantung}

Beberapa isu terkait tentang jantung akan dijabarkan secara singkat dalam sub bab ini, yaitu :

\section{Organ Jantung}

Jantung merupakan organ vital yang berfungsi untuk mensuplai darah yang berisi oksigen dan zat-zat lain yang diperlukan oleh tubuh. Jantung bekerja dengan cara memompa, agar darah dapat didistribusikan ke seluruh bagian tubuh.

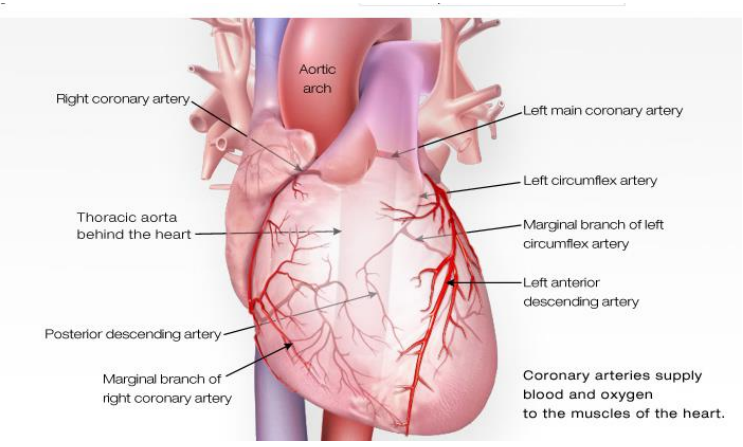

Gambar 2.1. Jantung Manusia [15]

2. Penyakit Jantung
Otot jantung membutuhkan oksigen untuk dapat bekerja menjalankan fungsinya sebagai penyuplai darah ke seluruh tubuh.Serangan jantung terjadi ketika aliran darah yang membawa oksigen ke otot jantung berkurang maupun terhenti. Hal tersebut terjadi dikarenakan oleh arteri coroner yang berfungsi untuk menyuplai darah ke jantung terganggu (lihat gambar 2.2) akibat timbunan lemak dalam darah, kolesterol, dan substansi lain yang disebut plaque [15]. Peristiwa tersebut disebut artherosclerosis yang kemudian dalam kondisi paling berbahaya adalah dapat terhentinya suplai darah ke jantung lalu menyebabkan kematian.

Heart failure[17]adalah suatu kondisi dimana jantung tidak mampu memompa darah sebagaimana seharusnya. Jantung tetap bekerja menjalankan fungsinya namun tubuh tidak mendapatkan supply darah dan oksigen sebanyak yang dibutuhkan..Gejala awal yang umum dialami pada terduga penyakit jantung adalah :

- Berkeringat di kaki, ankle, dan kaki. Gejala ini disebut dengan edema.

- Terdapat cairan berlebihan pada paruparu yang disebut pulmonary congestion.
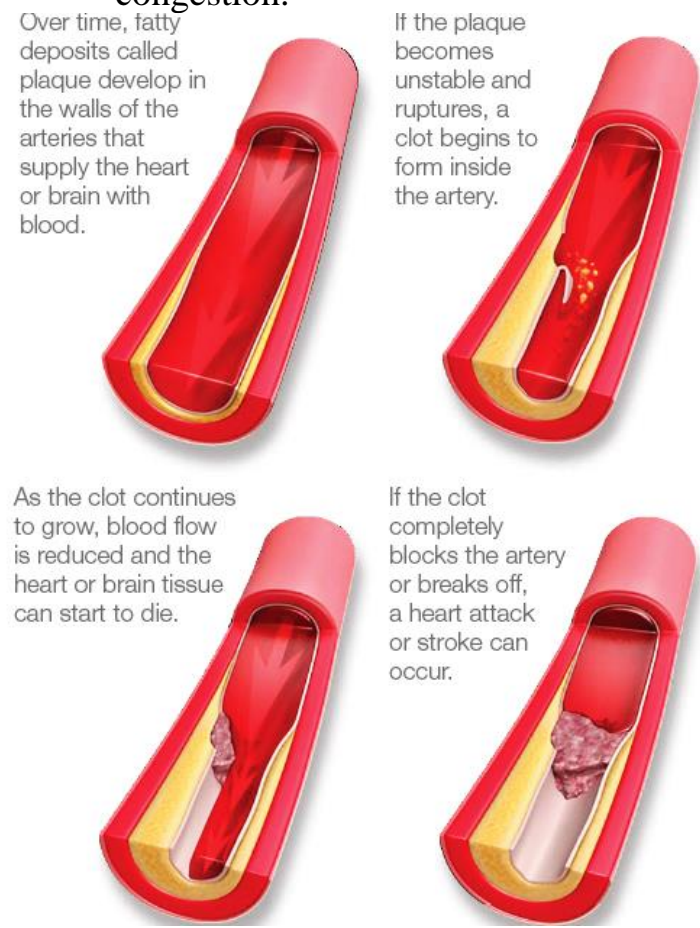

Gambar 2.2. Penyumbatan Pembuluh Darah

[15] 


\section{B. Deteksi Penyakit Jantung}

Berikut adalah beberapa penelitian yang telah dilakukan dalam upaya deteksi penyakit jantung :

1. Prediksi Penyakit Jantung Koroner Menggunakan Kategori Faktor Resiko

Peter W. F. Wilson et al [5] meneliti suatu komunitas sebanyak 2489 pria dan 2856 wanita berusia 30 74 tahun yang mana diketahui bahwa 383 pria dan 227 wanita positif mengidap penyakit jantung koroner. Faktor yang mempengaruhi penyakit jantung koroner ini antara lain usia, tekanan darah, kolesterol total, kolesterol LDL, kolesterol HDL, diabetes, dan merokok.

Pada penelitian Peter W. F. Wilson et al [5] ini, pasien yang memiliki tekanan darah melebihi 130/85 mm Hg, diketahui bahwa $28 \%$ pria dan $29 \%$ wanita mengidap penyakit jantung koroner. Sedangkan pasien yang memiliki kolesterol melebihi 200 $\mathrm{mg} / \mathrm{dl}$, diketahui bahwa $27 \%$ pria dan $34 \%$ wanita mengidap penyakit jantung koroner.

2. Diagnosa Penyakit Jantung Menggunakan Fuzzy

Ali Adeli dan Mehdi Neshat [10] melakukan penelitian untuk membangun sebuah sistem komputasi untuk mendiagnosa penyakit jantung yang berkemampuan layaknya seorang pakar dan dapat digunakan sendiri oleh para pasien. Sistem pakar ini menggunakan hasil uji laboratorium untuk dijadikan sebagai input untuk kemudian diproses dan menghasilkan output yang menentukan seseorang mengidap penyakit jantung atau tidak.

Ali Adeli dan Mehdi Neshat [10] menggunakan dataset jantung yang berasal dari repositori University of California Irvine (UCI) [13] yang terdiri dari 303 dataset dengan 14 atribut, tetapi yang digunakan hanya 11 atribut sebagai input (chest pain type, blood pressure, cholesterol, resting blood sugar, maximum heart rate, resting electrocardiography (ECG), exercise, old peak, thallium scan, sex dan age), dan 1 atribut sebagai output/result. Dari pengolahan dataset dengan menggunakan logika Fuzzy pada Matlab[10], akurasi yang mampu dicapai adalah $94 \%$.

3. Desain Sistem Pakar Fuzzy Pendeterminasi Resiko Penyakit Jantung Koroner

Novruz Allahverdi, Serhat Torun, dan Ismail Saritas [7] mendesain sebuah sistem pakar berbasis Fuzzy untuk mendeteksi penyakit jantung serta persentasi resiko yang dialaminya. Dengan menggunakan dataset dari UCI Repository sebanyak 270 data pasien dengan 14 atribut (age, sex, chest pain type, resting blood pressure, cholesterol, fasting blood sugar, resting ECG, average heart rate, examine induced angina, T or ST oldpeak, ST slope, number of major vessels, general heart rate, dan num(result)), lalu mengolahnya menggunakan Matlab dan Visual Basic, mereka mampu mencapai akurasi sebesar $79 \%$ untuk mendeteksi penyakit jantung koroner sekaligus persentasi resiko yang dihadapinya, misalkan pasien dinyatakan sehat namun memiliki $15 \%$ resiko untuk mengidap penyakit jantung koroner.

4. Pembelajaran Pola Penyakit Jantung Koroner menggunakan Pohon Keputusan

Huihui Zhao et al [8] melakukan penelitian untuk mencari pola hubungan penyakit jantung koroner dengan sindrom Blood Stasis dengan menggunakan Pohon Keputusan. Atribut yang mereka digunakan antara lain : blood glucose (GLU), high density lipoprotein (HDL), low density lipoprotein (LDL), cholesterol (CHO), triglyceride (TG), hemoglobin (HGB), 
white blood count (WBC), red blood count (RBC), platelet count (PLT), neutrophilic granulocyte absolute value (NE), leukomonocyte absolute value (LY). Dengan menggunakan algoritma C5.0, akurasi yang mampu dicapai adalah $82 \%$.

\section{METODOLOGI}

Secara garis besar, penelitian ini akan dilakukan dalam beberapa tahapan seperti studi literatur, pengumpulan data, membangun model sistem deteksi, melakukan testing dan evaluasi model (lihat pada Gambar 3. 1).

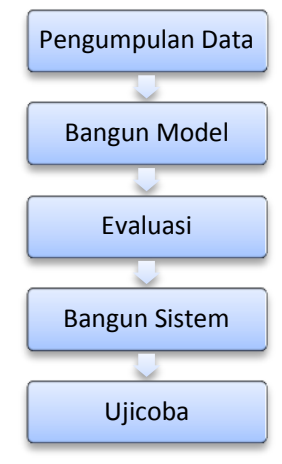

Gambar 3.1. Alur Penelitian

\section{A. Data}

Eksperimen ini akan menggunakan sebanyak 294 dataset pasien yang berasal dari repository University of California Irvine (UCI) [13]. Dataset tersebut terdiri atas 14 atribut, yaitu :

1. Age : umur pasien.

2. Sex : Jenis kelamin pasien.

3. Cp : tipe nyeri dada yang diderita pasien. Atribut ini memilik 4 nilai, yaitu :

- Tipe 1 : typical angina

- Tipe 2 : atypical angina

- Tipe 3 : non-anginal pain

- $\quad$ Tipe 4 : asymptomatic
4. Trestbps :resting blood pressure yaitu tekanan darah pasien ketika dalam keadaan istirahat. Satuan yang dipakai adalah $\mathrm{mm} \mathrm{Hg}$.

5. Chol :Cholesterol yaitu kadar kolesterol dalam darah pasien, dengan satuan $\mathrm{mg} / \mathrm{dl}$.

6. Fbs :fasting blood sugar yaitu kadar gula darah pasien, atribut fbs ini hanya memiliki 2 nilai yaitu 1 jika kadar gula darah pasien lebih dari $120 \mathrm{mg} / \mathrm{dl}$, dan 0 jika kadar gula darah pasien kurang dari sama dengan $120 \mathrm{mg} / \mathrm{dl}$.

7. Restecg :resting electrocardiographic yaitu kondisi ECG pasien ketika dalam keadaan istirahat. Atribut ini memiliki 3 nilai yaitu nilai 0 untuk keadaan normal, nilai 1 untuk keadaan ST-T wave abnormality yaitu keadaan dimana gelombang inversions $\mathrm{T}$ dan atau ST meningkat maupun menurun lebih dari $0,5 \mathrm{mV}$, dan nilai 2 untuk keadaan dimana ventricular kiri mengalami hipertropi.

8. Thalach : rata-rata detak jantung pasien.

9. Exang : keadaan dimana pasien akan mengalami nyeri dada apabila berolah raga, 0 jika tidak nyeri, dan 1 jika menyebabkan nyeri.

10. Oldpeak : penurunan ST akibat olah raga.

11. Slope :slope dari puncak ST setelah berolah raga. Atribut ini memiliki 3 nilai yaitu 1 untuk upsloping, 2 untuk flat, dan 3 untuk downsloping.

12. Ca : yaitu banyaknya pembuluh darah yang terdeteksi melalui proses pewarnaan flourosopy.

13. Thal : detak jantung pasien. Atribut ini memiliki 3 nilai yaitu 3 untuk normal, 6 untuk fixed defect, dan 7 untuk reversal defect.

14. Num : hasil diagnosa penyakit jantung.

Dataset tersebut kemudian akan diolah menggunakan algoritma $\mathrm{C} 4.5$ yang terdapat pada Weka [6] [7]. Algoritma C 4.5 pada Weka dikenal dengan nama J48. 


\section{B. Peralatan Penelitian}

Adapun beberapa instrument yang akan digunakan dalam penelitian ini terdiri dari :

1. Personal Computer (PC) yang digunakan untuk melakukan eksperimen serta membangun model deteksi penyakit jantung.

2. Aplikasi Weka untuk membangun rule model program. Aplikasi ini akan di-install pada PC dan laptop yang digunakan selama eksperimen penelitian.

3. Java SE Development Kit (JDK) dan Android Studio untuk membangun dan mensimulasikan program.

\section{HASIL}

A. Model

Dari dataset yang digunakan dan diolah menggunakan algoritma $\mathrm{C} 4.5$ atau yang lebih dikenal dengan Pohon Keputusan (Decision Tree) yang terdapat pada Weka [7], dihasilkan model seperti Gambar 4.1. Model pada Gambar 4.1 kemudian akan diimpelementasikan sebagai rules pada aplikasi diagnosa penyakit jantung pada ponsel dengan sistem operasi Android.

\section{B. Evaluasi}

Evaluasi model pada penelitian ini adalah menggunakan penghitungan akurasi yaitu seberapa dekat model yang dihasilkan dalam menentukan data sesuai keadaan yang sebenarnya.Akurasi yang diperoleh dalam penelitian ini mampu mencapai angka 81,29\% dengan rincian confusion matrix sebagai berikut:

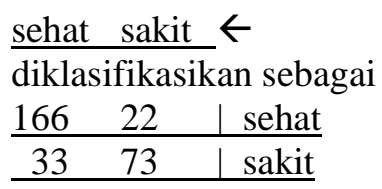

Dari total 294 data yang terdiri dari 188 pasien sehat dan 106 pasien sakit, ternyata hanya 239 pasien yang berhasil diklasifikasikan sesuai dengan kelasnya, sedangkan sisanya diklasifikasikan kedalam kelas yang salah. Dari 188 pasien sehat, hanya 166 yang diklasifikasikan sebagai pasien sehat, sehingga terjadi 22 pasien yang salah dinyatakan sebagai sakit. Dari 106 pasien sakit, hanya 73 yang berhasil dinyatakan sebagai pasien sakit sedangkan 33 pasien sakit lainnya dinyatakan sebagai pasien sehat.

\section{Implementasi Model \\ Setelah mendapatkan model klasifikasi,} langkah selanjutnya adalah dengan mengimplementasikan model yang dihasilkan oleh Pohon Keputusan menggunakan Weka (lihat Gambar 4.1) ke dalam bahasa pemrograman Java untuk kemudian dapat digunakan pada ponsel berbasis Android. Hasil dari implementasi rules yang dihasilkan oleh Pohon Keputusan dapat dilihat pada Gambar 4.2.

Pada Gambar 4.2 dapat dilihat tampilan pada layar ponsel berbasis Android ketika aplikasi sedang dijalankan. Pada sesi awal, pengguna diminta untuk mengisi data nama, umur, dan jenis kelamin. Setelah pengguna memasukkan nama, umur, dan jenis kelamin, kemudian proses mendiagnosa akan dilanjutkan dengan 12 pertanyaan sesuai dengan data yang telah dijabarkan pada poin III. Metodologi di atas.

Pada akhir sesi pengisian form pertanyaan, sistem akan memulai melakukan penarikan kesimpulan dengan berdasar if... then ... rules sesuai model yang telah dibangun menggunakan Weka. Hasil diagnosa yang akan ditampilkan sebagai penarikan kesimpulan pada aplikasi ini hanya memiliki 2 nilai yaitu sakit atau sehat.

Pada pasien yang didiagnosa sehat, mungkin tidak perlu melakukan pemeriksaan lanjut. Namun bagi pasien yang didiagnosa sebagai sakit sebaiknya dilakukan pemeriksaan lanjut serta diberi tindakan dan pengobatan sesuai dengan tata laksana medis pada penderita penyakit jantung 


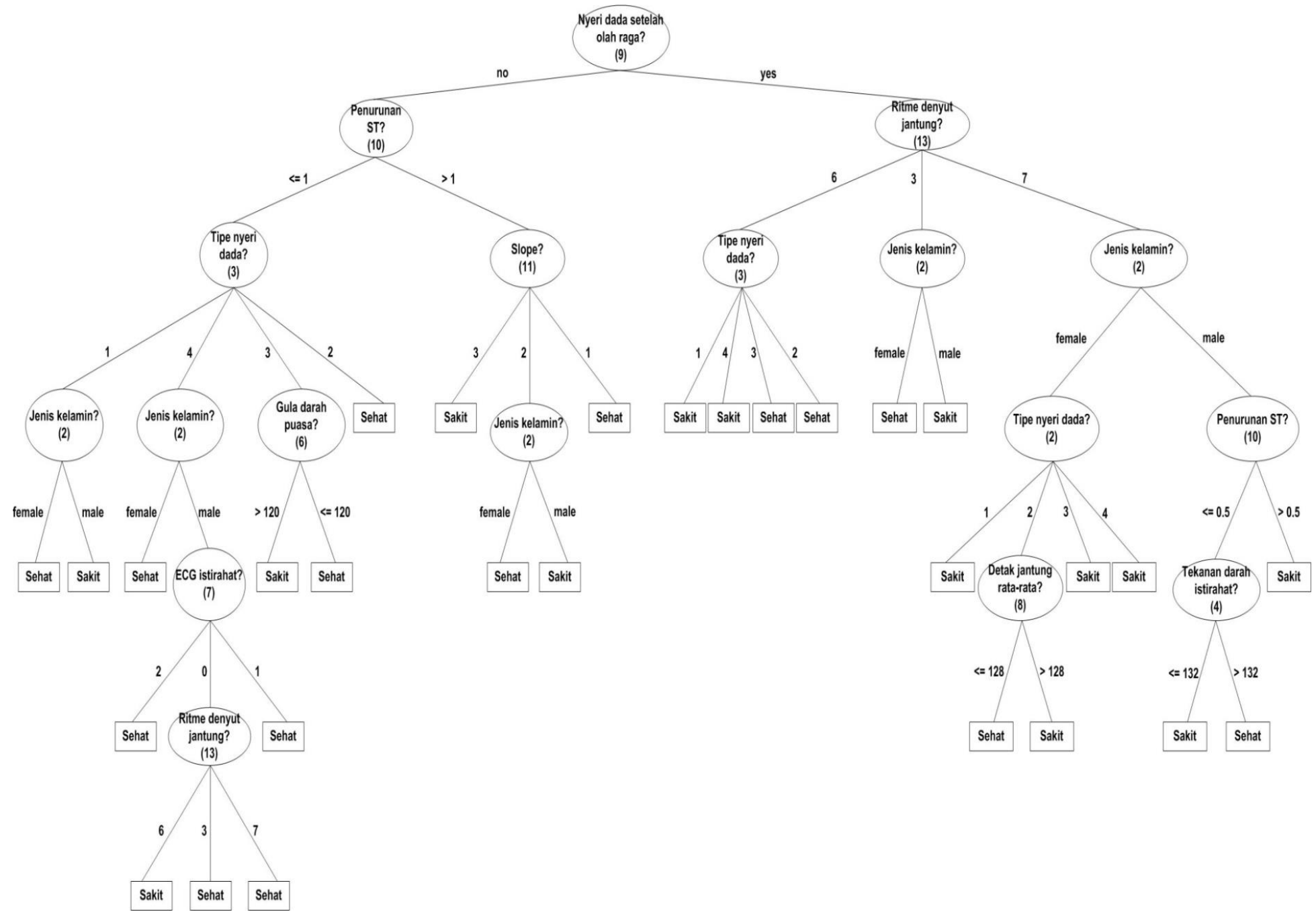

Gambar 4.1. Hasil Model Pohon Keputusan 


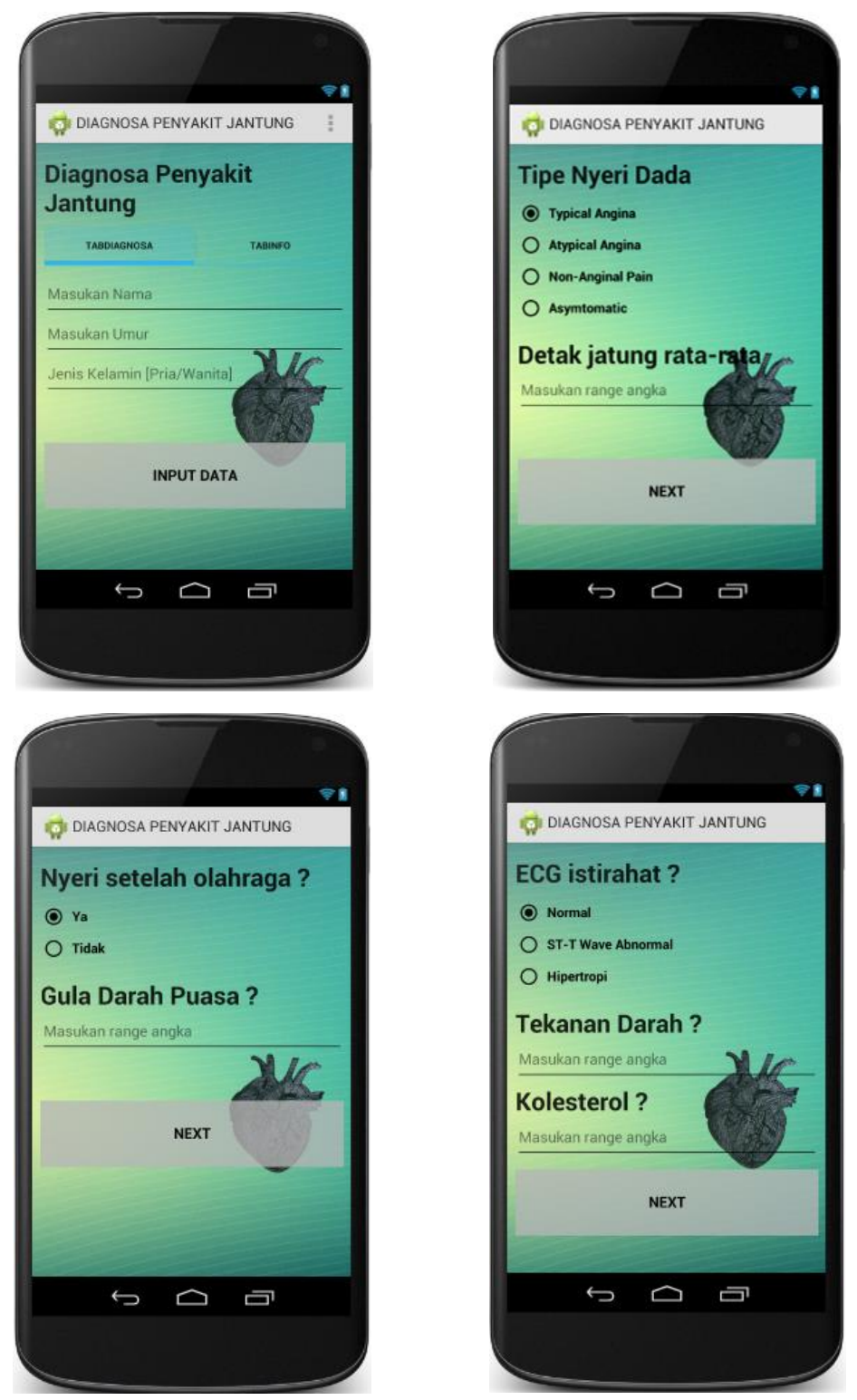

Gambar 4.2. Tampilan layar aplikasi Diagnosa Penyakit Jantung

\section{KESIMPULAN}

\section{A. Kesimpulan}

Kesimpulan yang dapat ditarik dari penelitian dalam membangun aplikasi untuk mendiagnosa penyakit jantung pada ponsel adalah sebagai berikut :

1. Pohon Keputusan yang digunakan sebagai pemodelan dalam kasus Penyakit Jantung pada dataset 294 pasien pada penelitian ini mampu menghasilkan tingkat akurasi yang cukup tinggi yaitu $81,29 \%$.
2. Pengimplementasian model klasifikasi penyakit jantung dengan menggunakan Pohon Keputusan pada ponsel dengan sistem operasi Android akan mempermudah praktisi kesehatan untuk menentukan apakah seorang pasien menderita penyakit jantung atau tidaksecara cepat dan akurat.

\section{B. Saran}

Saran yang dapat diberikan berdasarkan hasil penelitian ini adalah: 
1. Perlu adanya penambahan jumlah data untuk menghasilkan tingkat akurasi yang lebih tinggi.

2. Perlu adanya classifier pembanding dalam klasifikasi penyakit jantung.

3. Perlu adanya pencarian pengatur parameter yang tepat dalam classifier agar menghasilkan tingkat akurasi yang lebih tinggi.

\section{DAFTAR PUSTAKA}

[1] Departemen Kesehatan RI. KMK No.854

Tentang Pengendalian Penyakit Jantung.

Menkes RI. Jakarta. 2009.

$<$ http://www.hukor.depkes.go.id/up_prod _kepmenkes/KMKNo854Tahun2009ttgP engendalianPenyakitJantung.pdf>

[2] Allahverdi, Novruz, Serhat Torun, Ismail Saritas. Design of Fuzzy Expert System For Determining of Coronary Hearth Disease Risk. International Conference on Computer Systems and Technologies. 2007.

[3] Machine Learning http://web.cecs.pdx.edu/ mm/MachineLe arningSpring2007/DarinMorrison.pdf

[4] Proceedings of the Second International Conference on Knowledge Discovery and Data Mining, 1996. <http://www.sc.ehu.es/ccwbayes/docenci $\mathrm{a} / \mathrm{mmcc} /$ docs/lecturasclasificacion/NBTree.pdf>

[5] DMS Tutorial - Pohon Keputusans. <http://dms.irb.hr/tutorial/tut_dtrees.php>

[6] Witten, Ian $\mathrm{H}$, et al. Weka: Practical Machine Learning Tools and Techniques with Java Implementations. Department of Computer Science University of Waikato. New Zealand. 2007.

[7] Weka 3 - Data Mining with Open Source Machine Learning Software in Java. <http://www.cs. waikato.ac.nz/ml/weka/>

[8] Digital Library Telkom Institute of Technology. <http://digilib.ittelkom.ac.id/index.php?o ption $=$ com_content $\&$ view $=$ article $\& i d=70$ 5:dest-ree\&catid=13:rpl\&Itemid=14>

[9] Wilson, Peter W. F., et al. Prediction of Coronary Heart Disease Using Risk Factor Categories. Circulation, The American Heart Association. Dallas. 1998.

$<$ http://circ.ahajournals.org/content/97/18 /1837>

[10] Adeli, Ali, Mehdi Neshat. A Fuzzy Expert System for Heart Disease Diagnosis. Proceedings of the International MultiConference of Engineers and Computer Scientists. 2010.

[11] C4.5: programs for machine learning, Oleh John Ross Quinlan, morgan Kauffmann, Sydney, 1992.

[12] Zhao, Huihui, et al. Characteristic Pattern Study of Coronary Heart Disease with Blood Stasis Syndrome Based on Pohon Keputusan. IEEE. 2010.

[13] UCI Machine Learning Repository. http://archive.ics.uci.edu/ml/

[14] James Dougherty, Ron Kohavi, Mehran Sahami. Supervised and Unsupervised Discretization of Continuous Features. Proceedings of the Twelfth International Conference, 1995, Morgan Kaufmann Publishers, San Francisco, CA http://www.math.unipd.it/ dulli/corso04/ disc.pdf

[15] American Heart Association. About Heart Attack.

2012.<http://www.heart.org/HEARTOR G/Conditions/HeartAttack/AboutHeartAtt acks/About-Heart-

Attacks_UCM_002038_Article.jsp>

[16] American Heart Association, 2007 http://www.heart.org/idc/groups/heartpublic/@wcm/@hcm/documents/downlo adable/ucm_300313.pdf

[17] WHO. Cardiovascular Disease Factsheets. WHO Media Centre. 2013. http://www.who.int/mediacentre/factsheet s/fs317/en/ 